\title{
Posttraumatic Stress Disorder among Patients at an Anxiety Clinic in Puerto Rico
}

\section{Desorden de Estrés Postraumático en Pacientes de una Clínica de Ansiedad en Puerto Rico}

\author{
Marie Torres-Valentín ${ }^{1 *}$, Karen G. Martínez-González ${ }^{2}$, \& Alfonso Martínez-Taboas ${ }^{3}$
}

1 University of Puerto Rico, Medical Sciences Campus, San Juan, Puerto Rico. (D) https://orcid.org/00000002-7254-6489

2 University of Puerto Rico, Medical Sciences Campus, San Juan, Puerto Rico. (D) https://orcid.org/00000001-7011-2751

3 Interamerican University of Puerto Rico, Metropolitan Campus, San Juan, Puerto Rico. (i) https://orcid.org/0000-0001-8331-0423

* Correspondence: mtorresv1@gmail.com

Received: 7 April 2021 | Accepted: 18 April 2021 | Published: 29 July 2021

\author{
WWW.REVISTACARIBENADEPSICOLOGIA.COM
}

\section{Citar como:}

Torres-Valentín, M., Martínez-González, K. G., \& Martínez-Taboas, A. (2021). Posttraumatic Stress Disorder among patients at an anxiety clinic in Puerto Rico. Revista Caribeña de Psicología, 5, e5527.

https://doi.org/10.37226/rcp.v5i1.5527

\begin{abstract}
Specialized evidence-based clinics are available for psychological trauma treatment. Data from patients in these clinics must be analyzed in order to better understand this population. In this study, we described the sociodemographic and clinical profile of patients from an evidence-based, anxiety disorder treatment/research center, located in the metropolitan area of Puerto Rico: The Center for the study of Fear and Anxiety (known by its Spanish acronym, CETMA). We performed a secondary data analysis of CETMA database, with data from the multidimensional evaluation, performed at the initial screening interview. We identified 35 patients with a preliminary diagnosis of PTSD. Patients with PTSD were mostly women, between 19-30 years, single, employed, with a completed bachelor's degree. Also, they had 2-4 diagnoses, the most common comorbidity was generalized anxiety disorder. They reported a previous psychiatric history of PTSD, depression, and panic attacks. On average, patients received 1-15 therapeutic sessions. Findings highlight the need for educating and disseminating these services to the public, a population with an increased risk for PTSD.
\end{abstract}

Keywords: anxiety clinic, database, Posttraumatic Stress Disorder, PTSD, Puerto Rico

\section{RESUMEN}

Existen clínicas especializadas, basadas en evidencia para tratamiento sobre trauma psicológico. Los datos de los pacientes de estas clínicas deben analizarse para comprender mejor esta población. En esta investigación, describimos el perfil sociodemográfico y clínico de investigación y tratamiento para pacientes que experimentan desórdenes de ansiedad y PTSD, localizada en el área metropolitana de Puerto Rico: el Centro para el Estudio y Tratamiento del Miedo y la Ansiedad (CETMA). Hicimos un análisis secundario de la base de datos de CETMA, con datos de la evaluación multidimensional realizada en la entrevista de cernimiento inicial. Identificamos 35 pacientes con un 
diagnóstico preliminar de PTSD. Estos pacientes eran mujeres en su mayoría, entre las edades de 19-30 años, solteras, empleadas, con un grado completado de bachillerato. Adicional, tenían entre 2-4 diagnósticos. La comorbilidad más común era el desorden de ansiedad generalizada. Reportaron un historial psiquiátrico previo de PTSD, depresión, y ataques de pánico. En promedio, los pacientes recibieron entre 1-15 sesiones. Los resultados resaltan la necesidad de educar y diseminar estos servicios al público, una población en riesgo de experimentar PTSD.

Palabras Claves: base de datos, clínica de ansiedad, desorden de estrés postraumático, Puerto Rico

\section{INTRODUCTION}

Puerto Rico recently experienced two high magnitude events: 2017's Hurricane María, and the 2020 earthquakes, affecting many individuals living in the island. Other highly stressful and potentially traumatic events (PTE), such as the current coronavirus pandemic, and random events occurring in people's personal lives, are an imminent threat to psychological balance, especially for those already receiving mental health treatment.

Posttraumatic Stress Disorder (PTSD) is a debilitating mental disorder and a public health problem (Ishimura et al., 2015; Bovin et al., 2015). The lifetime prevalence of PTSD is 3.5 to $9.2 \%$ among persons exposed to PTE, and PTSD may become chronic in as many as $42 \%$ of individuals who develop the illness (Spinhoven et al., 2014; Kilpatrick et al., 2017). Although the trauma literature states that most people are resilient (i.e., able to face hardship with minimal symptoms), a significant number have long-term symptoms and is unable to recover (Magruder et al., 2017). People with PTSD are more likely to have comorbidity with other mental disorders. High ranges of depression (21 to 94\%) and anxiety (39 to 97\%) have been found in persons with PTSD (Ginzburg et al., 2010; Bovin, et al., 2015). Substance-related disorders are also common (Souto de Castro Longo et al., 2020). PTSD is also associated with physical diseases such as diabetes, obesity, angina, hypertension, gastritis, and arthritis (Chang et al., 2017; Kitsmiller, 2017; Gabalawy et al., 2018).

In PTSD, the recommended first-line treatment are psychological therapies (Lewis et al., 2020). Limited knowledge of services based on gold standard, evidence-based treatments may cause treatment delay and higher costs. Decreased quality of life, diminished productive capacity and welfare dependency are only a few of the individual and social problems when an effective treatment is not available (Frueh et al., 2018). If untreated, PTSD contributes to substance abuse, job loss, and suicide (Tarrier, \& Gregg, 2004; Bovin et al., 2015). When diagnosed in minorities, PTSD is often undertreated (Chang et al., 2017).

Almost $45 \%$ of the Puerto Rican population live below the poverty line (United States Census, 2019). Social and economic factors may contribute to greater psychopathology after exposure to PTE. Low socioeconomic status (SES) is a risk factor for multiple exposures and worst outcomes, and for experiences of discrimination, barriers to health care services, and lower quality services (Overstreet et al., 2016; Valentine et al., 2020).

In Puerto Rico, PTSD has been studied with college students (Bahamonde, 2006), primary care patients (Vera et al., 2012), and male adult caretakers from the Neonatal Twin Registry (Overstreet et al., 2016). After hurricane María, studies on PTSD centered on school-aged students (Orengo-Aguayo et al., 2019), and adults in Puerto Rico during the hurricane (Scaramutti et al., 2019). PTSD rates in these studies ranged from $6.7 \%-43.6 \%$. To date, there is no recent published data on PTSD and associated problems in treatment-seeking individuals of specialized mental health clinics in Puerto Rico.

We performed this research study because of the high prevalence of posttraumatic stress symptoms reported in previous studies with Puerto Ricans, and the lack of current data on patients' characteristics from evidence-based clinics. The current study had two objectives. First, we determined the sociodemographic and clinical profile of patients with a preliminary PTSD diagnosis from the Center for the Study of Fear and Anxiety (known by its Spanish acronym, CETMA, Centro de Estudio y Tratamiento para el Miedo y la Ansiedad (CETMA), a clinic that provides evidence-based treatment for anxiety disorders. Second, we evaluated associations with sociodemographic and clinical variables, in terms of the presence or absence of a PTSD diagnosis. 


\section{METHOD}

\section{Research Design}

This research study followed a descriptive design. It was a secondary analysis from a patients' database, originally developed for the following study: Describing ataque de nervios among patients at CETMA anxiety Clinic (Approval \#A3910119). The original research study evaluated the clinical presentation, associated comorbidities, \& demographic characteristics of patients with Ataque de Nervios (AdN) at CETMA anxiety clinic, and developed/validated an AdN screening questionnaire for Puerto Ricans (Subervi et al., 2020). The IRB approved the data recollection form, its data analysis, \& evaluation of clinical diagnoses, for the original and subsequent studies.

CETMA is a specialized, interdisciplinary clinic, created in 2012 and affiliated to the Medical Sciences Campus, University of Puerto Rico (MSC-UPR), and provides culturally adapted, evidence-based psychotherapies for anxiety and trauma-related disorders, including prolonged exposure (PE) for the treatment of PTSD. To the best of our knowledge, this is the only clinic in Puerto Rico whose services are completely evidence-based. The center also provides psychiatric services, by an alliance with the Psychiatry Clinic, affiliated to the MSC-UPR.

Patients may receive services at CETMA if they are 18 years old, and older, are able to provide informed consent to the initial evaluation/treatment process, and if their main diagnosis is an anxiety disorder, or PTSD. To be accepted for services, patient must not have any psychotic, or substance-related disorder.

\section{Procedures}

The database contained demographic and clinical characteristics of patients from CETMA. This database was based on the data collection form, used to gather data from the initial interview, performed to screen patients with anxiety disorders. Medical students, psychiatry residents from MSC-UPR and graduate students/interns in clinical psychology from Ponce Health Sciences University performed the initial screening interviews. The CETMA Clinical Director supervised these students.
For this study, we chose the following demographic variables: gender, age, highest completed education, occupational status, and marital status. We also chose the following clinical variables: initial screening interview date, screening questions for PTSD, comorbidities, previous psychiatric history, diagnoses given at the center, Beck Depression Inventory-II results, and discharge and/or treatment summary.

Cases in the database were divided in two groups: 1) Patients with PTSD were those who received a preliminary diagnosis of PTSD on their initial screening interview (According to the Diagnostic and Statistical Manual, DSM version used at the time of the interview), 2) Patients with no PTSD were those who did not receive a preliminary diagnosis of PTSD on the screening interview, and received an anxiety disorder diagnosis.

\section{Measures}

Data collection form. A fifteen-page data collection form, containing patient's sociodemographic and clinical information, taken at the initial screening interview. As stated before, the database contained each variable from this form.

Beck Depression Inventory-II, Spanish version (Spanish BDI-II). The database also contained the results of several questionnaires, administered at the initial screening interview. For this research study, we analyzed results from the Spanish version of the Beck Depression Inventory-II (Spanish BDI-II). The Spanish BDI-II is a 21 item, multiple choice, self-report inventory, widely used for detecting severity of depression, in persons 13 to 80 years old. In terms of psychometric properties, the BDI-II has a strong, threefactor structure, a 0.91 Cronbach's alpha coefficient, and satisfactory validity and reliability indices in each domain (González-Barrios, et al., 2016).

\section{Data Analysis}

The database was developed in Excel, and statistical analyses were performed in Stata SE. For missing values, we carefully examined qualitative items to fill missing information. We then replaced missing values from categorical variables with its mode, and the mean of each numerical variable. This procedure was performed if fewer than $25 \%$ of the values were missing. For the date of initial interviews, previous 
psychiatric history and comorbidities, we added an additional category (unspecified) for missing values. Statistical analyses included the following descriptive analyses: frequency distributions, and percentages for specific sociodemographic variables, in terms of the whole sample, and in terms of the previously specified patient groups (patients with PTSD, and patients without a PTSD diagnosis). We also used frequency distributions and percentages to obtain the most diagnosed anxiety disorders at the center, and the most common comorbidities for each group. Means and standard deviations were computed for the number of comorbidities, and the number of sessions at the center. We also performed chi square analyses to identify associations with sociodemographic and categorical clinical variables, in terms of presence or absence of PTSD. We also computed logistic regression analyses to estimate the association with previous psychiatric history, and number of comorbidities, also in terms of presence or absence of PTSD.

\section{RESULTS}

\section{Sociodemographic characteristics}

Total sample. The database included 199 cases. Two cases were excluded; one case was repeated, and another case had multiple missing data points. Thus, we used a sample of 197 patients for analyses. In the total sample, $62.9 \%$ of patients were females $(n=124)$, while $37.1 \%$ were males $(n=73)$. Most patients were single $(n=107,54.3 \%)$, and completed a bachelor's degree $(52.79 \%)$. Patients ranged between $19-76$ years old (Table 1).

Patients with PTSD. Within the sample, 17.77\% met criteria for PTSD $(n=35)$. For patients with PTSD, $57.14 \%$ were females $(n=20)$, while $42.83 \%$ were males $(n=15)$. They ranged between 20-73 years of age; the majority were between 19-30 years. In terms of marital status, $57.14 \%$ of patients with PTSD were single $(n=20)$, and the majority completed a bachelor's degree: $(n=20,57.14 \%)$. Summary of demographic characteristics for the total sample and groups with and without PTSD is included in Table 1.

No statistical associations were found between diagnostic groups (presence or absence of PTSD) and the following sociodemographic variables: gender, age, and highest completed education. Chi square analyses showed significant associations with marital status ( $p=.000)$, and occupational status $(p=.023)$. In the logistic regression analysis of marital status, divorced individuals were 2.99 times more likely to have PTSD (95\%CI 1.21-7.42, $p=.018)$.

Table 1

Demographic variables for patients included in the database.

\begin{tabular}{|c|c|c|c|c|c|c|}
\hline \multirow[t]{2}{*}{ Characteristic } & \multicolumn{2}{|c|}{$\begin{array}{c}\text { Total } \\
\text { sample } \\
(\mathrm{N}=197)\end{array}$} & \multicolumn{2}{|c|}{$\begin{array}{l}\text { PTSD } \\
(n=35)\end{array}$} & \multicolumn{2}{|c|}{$\begin{array}{c}\mathrm{No}_{\text {PTSD }}{ }^{\mathrm{a}} \\
(n=162)\end{array}$} \\
\hline & $n$ & $\%$ & $n$ & $\%$ & $n$ & $\%$ \\
\hline \multicolumn{7}{|l|}{ Gender } \\
\hline Female & 124 & 62.9 & 20 & 57.1 & 104 & 64.2 \\
\hline Male & 73 & 37.1 & 15 & 42.8 & 58 & 35.8 \\
\hline \multicolumn{7}{|l|}{ Age } \\
\hline 19-30 years & 82 & 41.6 & 14 & 40.0 & 68 & 42.0 \\
\hline $31-40$ years & 51 & 25.9 & 8 & 22.9 & 43 & 26.5 \\
\hline $41-60$ years & 51 & 25.9 & 10 & 28.6 & 41 & 25.3 \\
\hline 61-79 years & 13 & 6.6 & 3 & 8.6 & 10 & 6.2 \\
\hline \multicolumn{7}{|l|}{ Marital status ${ }^{b}$} \\
\hline Single & 107 & 54.3 & 20 & 57.1 & 87 & 53.7 \\
\hline Married/Partnership & 63 & 32.0 & 4 & 11.4 & 59 & 36.4 \\
\hline Divorced & 27 & 13.7 & 11 & 31.4 & 16 & 9.9 \\
\hline \multicolumn{7}{|l|}{ Education } \\
\hline High school/lower & 35 & 17.8 & 4 & 11.4 & 31 & 19.1 \\
\hline Associate/technical & 12 & 6.1 & 4 & 11.4 & 8 & 4.9 \\
\hline degree & 104 & 52.7 & 20 & 57.1 & 84 & 51.9 \\
\hline $\begin{array}{l}\text { Bachelor's degree } \\
\text { Postgraduate degree }\end{array}$ & 46 & 23.4 & 7 & 20.0 & 40 & 24.7 \\
\hline \multicolumn{7}{|l|}{ Occupational status c } \\
\hline Employed & 129 & 65.5 & 18 & 51.4 & 111 & 68.5 \\
\hline Student & 33 & 16.8 & 4 & 11.4 & 29 & 17.9 \\
\hline Unemployed & 28 & 14.2 & 10 & 28.6 & 18 & 11.1 \\
\hline Disabled & 2 & 1.0 & 1 & 2.9 & 1 & 0.7 \\
\hline Retired & 5 & 2.5 & 2 & 5.7 & 3 & 1.9 \\
\hline
\end{tabular}

Note. ${ }^{\mathrm{a}}=$ Patients diagnosed with anxiety disorders, other than PTSD. ${ }^{\mathrm{b}}(p=.000), \mathrm{c}(p=.023)$.

\section{Clinical Characteristics}

Initial interviews per year. The initial screening interviews included in this database were performed between July 17th, 2012 and October $16^{\text {th }}, 2019$. For each year, most of the preliminary diagnoses made at the initial interviews were anxiety disorders. In 2018 (hurricane Irma and María happened on September $4^{\text {th }}$, and September $20^{\text {th }}, 2017$, respectively) there was 
an increase in PTSD cases, compared with the previous three years (Figure 1).

Anxiety disorder diagnoses. Diagnosed disorders included all DSM-5 anxiety disorders. We also identified secondary diagnoses that were not anxietyrelated (e.g., neurocognitive disorder, major depression, specific personality disorders/features, \& bipolar disorder). In the database, generalized anxiety disorder (GAD) was the most diagnosed disorder. For patients with PTSD, GAD was the second most diagnosed disorder (Figure 2).

Comorbidities. For the total sample, $49.3 \%$ of patients had more than one psychiatric disorder $(n=97)$, ranging between 2-9 disorders. Additionally, 54.3\% of patients with PTSD had more than one psychiatric disorder $(n=19)$, ranging between 2-4 psychiatric disorders (Table 2). In the logistic regression model of comorbidities, we found that patients with three comorbidities were 2.63 times more likely to have a preliminary diagnosis of PTSD (95\%CI .72-9.66, $p=$ .145).

Psychiatric history of DSM-5 diagnoses and related problems. In the database, $31.5 \%$ of patients reported no psychiatric history of mental disorders $(n=$ 62). For patients with PTSD, 5.6\% reported no previous history of mental disorders $(n=11)$. In the database, the most common previously diagnosed disorders/problems were depression and panic attacks (Table 3). A chi square test showed significant associations between previous psychiatric history and the diagnostic groups $(p=.001)$. After applying a logistic regression analysis, in terms of PTSD diagnosis, we found that patients with a previous psychiatric history of PTSD, were 8.11 times more likely to have a current diagnosis of PTSD (95\%CI: 2.02-32.59, $p=$ .003).

Depression symptoms according to the BDI-II. In the total sample, $46.2 \%$ had a score ranging between mild to severe depression $(n=91)$. For patients with PTSD, 45.7\% showed scores ranging from mild to severe depression $(n=19)$. The majority of patients with and without PTSD had minimal symptoms of depression (Figure 3). The logistic regression model of depression levels in the BDI-II, showed that patients with severe depression were 2.38-fold more likely to have a diagnosis of PTSD (95\%CI 0.98-5.75, $p$ $=.054)$.
Figure 1

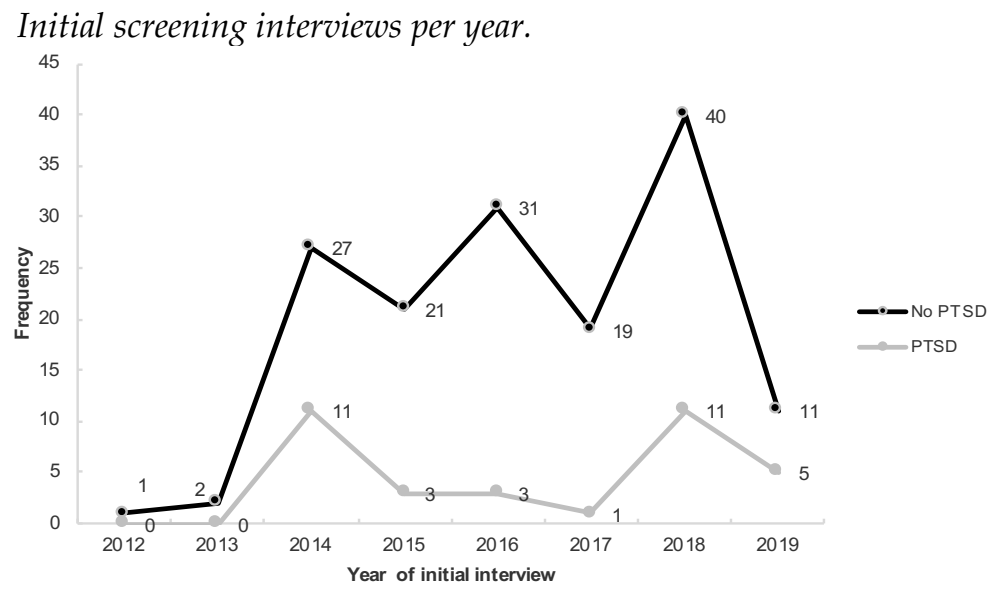

Note. Ten cases in the group of patients without PTSD, and one case in the group of patients with PTSD had no data on this variable, thus were not included in the figure.

Figure 2

Most diagnosed disorders, in terms of PTSD diagnosis.

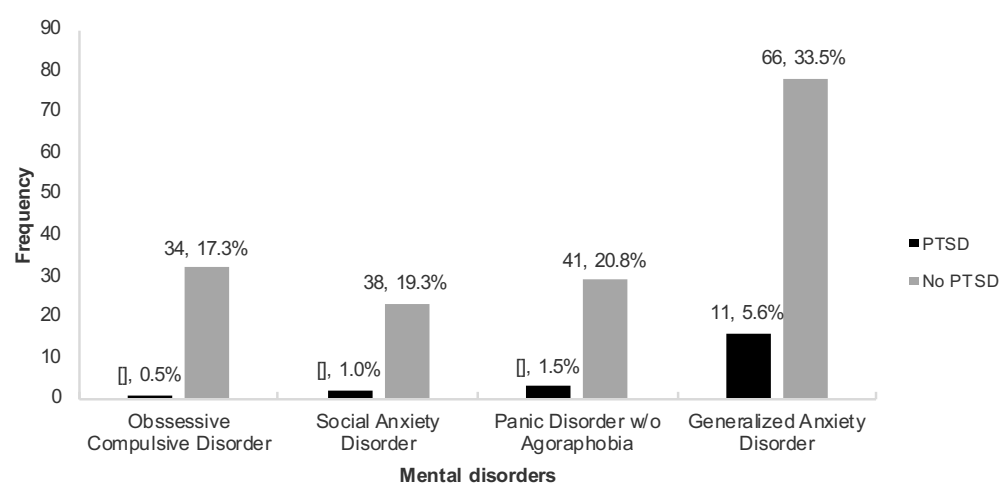

Table 2

Comorbidities in terms of presence or absence of a PTSD diagnosis.

\begin{tabular}{lcccccc}
\hline $\begin{array}{c}\text { Comorbidity } \\
\text { type }\end{array}$ & $\begin{array}{c}\text { Total sample } \\
(\mathrm{N}=197)\end{array}$ & $\begin{array}{c}\text { PTSD } \\
(n=35)\end{array}$ & $\begin{array}{c}\text { No PTSD } \\
(n=162)\end{array}$ \\
\hline Unspecified & 24 & $12.2 \%$ & 5 & $14.3 \%$ & 19 & $11.7 \%$ \\
No comorbidity & 76 & $38.6 \%$ & 11 & $31.4 \%$ & 65 & $40.1 \%$ \\
2 diagnoses & 66 & $33.5 \%$ & 9 & $25.7 \%$ & 57 & $35.2 \%$ \\
3-9 diagnoses & 31 & $15.7 \%$ & 10 & $28.6 \%$ & 21 & $13.0 \%$
\end{tabular}

Note. ${ }^{\mathrm{a}}=$ Patients diagnosed with anxiety disorders, other than PTSD. 
Table 3

Psychiatric history of DSM-5 mental disorders (and related experiences), in terms of presence or absence of PTSD.

\begin{tabular}{lcccccc}
\hline \multicolumn{1}{c}{ Disorder } & \multicolumn{2}{c}{$\begin{array}{c}\text { Total sample } \\
\end{array}$} & \multicolumn{2}{c}{$\begin{array}{c}\text { PTSD } \\
(N=197)\end{array}$} & \multicolumn{2}{c}{$\begin{array}{c}\text { No PTSD }^{\text {a }}(n=35) \\
(n=162)\end{array}$} \\
\cline { 2 - 7 } & $n$ & $\%$ & $n$ & $\%$ & $n$ & $\%$ \\
\hline Depression & 30 & $15.2 \%$ & 5 & $14.3 \%$ & 25 & $15.4 \%$ \\
Panic attacks & 26 & $13.2 \%$ & 4 & $11.4 \%$ & 22 & $13.6 \%$ \\
Anxiety symp. & 24 & $12.2 \%$ & 3 & $8.6 \%$ & 21 & $13.0 \%$ \\
OCD & 19 & $9.6 \%$ & 0 & $0.0 \%$ & 19 & $11.7 \%$ \\
PTSD & 10 & $5.1 \%$ & 7 & $20.0 \%$ & 4 & $2.5 \%$ \\
ADHD & 8 & $4.1 \%$ & 0 & $0.0 \%$ & 8 & $4.9 \%$ \\
Suicide attempt & 7 & $3.6 \%$ & 2 & $5.7 \%$ & 5 & $3.1 \%$ \\
Sexual/Physical & 3 & $1.5 \%$ & 2 & $5.7 \%$ & 1 & $0.62 \%$ \\
abuse & & & & & & \\
Substance abuse & 3 & $1.5 \%$ & 0 & $0.0 \%$ & 3 & $1.85 \%$ \\
Feeding disorder & 2 & $1.0 \%$ & 1 & $2.9 \%$ & 1 & $0.62 \%$ \\
Somatization & 2 & $1.0 \%$ & 0 & $0.0 \%$ & 2 & $1.23 \%$ \\
None & 62 & $31.5 \%$ & 11 & $31.4 \%$ & 51 & $31.5 \%$ \\
\hline
\end{tabular}

Note. ${ }^{\text {a }}=$ Patients diagnosed with anxiety disorders, other than PTSD.

\section{Figure 3}

BDI-II levels in patients with and without PTSD, at the initial screening interview.

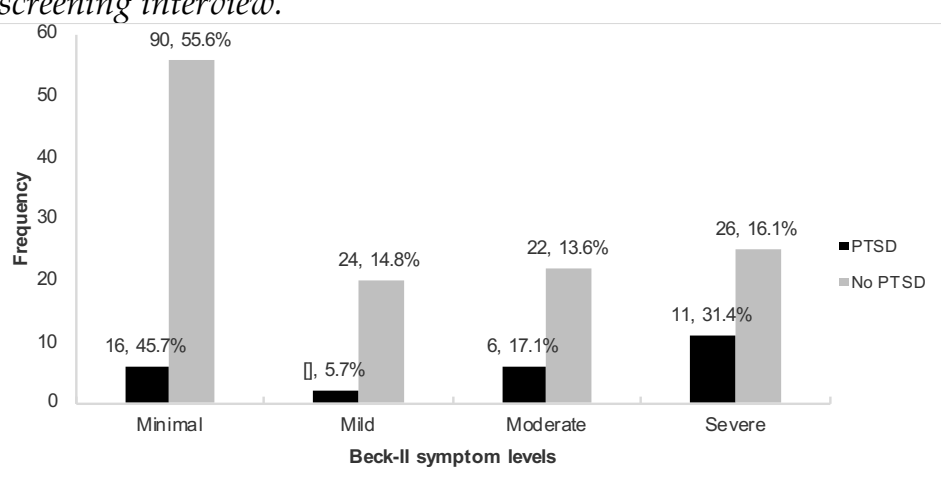

Figure 4

Descriptive analysis of reason for discharge.

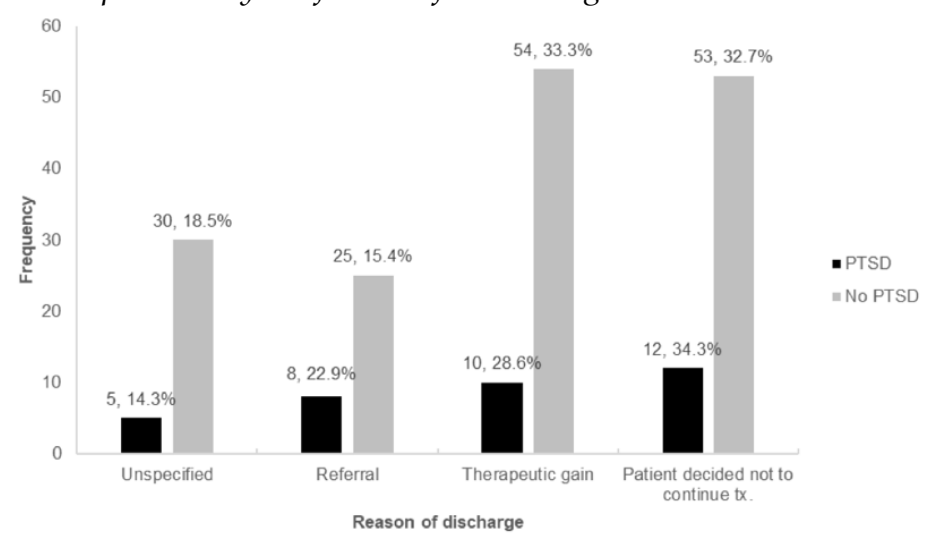

Total number of sessions. The database showed that patients had between one and 91 therapeutic sessions $(\mathrm{M}=17.57, \mathrm{SD}=15.20)$. When considering the number of visits, there were no significant differences in terms of having a current PTSD diagnosis or not. In the database, $32.5 \%$ of patients $(n=64)$, and $28.6 \%$ of patients with PTSD $(n=10)$ completed the treatment protocol with partial or full therapeutic gain. In the diagnostic groups, $34.3 \%(n=12)$ of patients with PTSD and $32.3 \%(n=53)$ of those without PTSD discontinued treatment for different reasons, including work-related conflict with appointments, and poor treatment adherence (Figure 4).

\section{DISCUSSION}

In this research study, we described the sociodemographic and clinical profile of patients with PTSD from CETMA, an evidence-based, anxiety clinic in Puerto Rico. In terms of sociodemographic characteristics, specifically gender, a higher frequency of women had a preliminary diagnosis of PTSD in the database, but we did not find statistical differences in terms of gender. This may be due to lack of statistical power, because of the small sample size of patients with PTSD. It is important to note that most of the patients in this database were women $(62.9 \%)$. It is well known that most of the patients who seek psychological services are women (Kitsmiller, 2017; Lewis et al., 2020). Also, 52.5\% of the Puerto Rican population are women (United States Census, n.d.).

In the analysis of the association between marital status and PTSD diagnosis, we found that divorced patients had higher odds of a preliminary PTSD diagnosis. Results from epidemiological studies in the US (Kessler, et al., 1995, Breslau et al., 1998), state that being previously married (separated, widowed, or divorced) is associated with an increased risk of PTSD (Kilpatrick, et al., 2017).

For the date of the initial screening interviews included in the database, we found that the years 2014 and 2018 had the higher frequencies of PTSD diagnoses. Hurricanes Irma and Maria happened in September 4th, and 20th, 2017, respectively, with catastrophic effects in many parts of the island. When comparing 2017 and 2018 cases, there was an increase of ten cases with PTSD in the year 2018. The database also showed that in the year 2019 (until October), five patients were diagnosed with PTSD. 
Though the number of PTSD cases per year is low, there was an increase in cases after the hurricanes. Research studies on posttraumatic stress symptoms and PTSD in Puerto Rico show a prevalence between $6.7 \%$ and $43.6 \% \%$, which is high when compared to epidemiological studies in the United States. Thus, services at CETMA are underused. Findings highlight the need for educational campaigns towards evidence-based treatments available, and for reducing stigma of seeking mental health treatment.

In terms of clinical characteristics, we found that GAD was the most common preliminary diagnosis in the database, and the most common comorbidity with PTSD. Patients were also screened for depression symptoms with the BDI-II. We found that $31.4 \%$ of patients with PTSD had symptoms of depression. According to the literature, patients with PTSD show comorbidities with depression, substance-related disorders, and other anxiety disorders. We did not specify comorbidities with substance-related disorders because having this type of disorder is an exclusion criterion for services at CETMA.

We also found that $25.8 \%$ of patients with PTSD showed a previous psychiatric history of PTSD. Patients with a previous psychiatric history of PTSD were also more likely to have a current PTSD diagnosis. This finding raises important questions regarding the type of treatment received before CETMA. A previous psychiatric history of PTSD may also affect current treatment response. PTSD may have negative consequences when facing subsequent exposures, such as revictimization risk, and poor protective measures against subsequent traumas.

The mean for the total number of sessions was 115 sessions. This is consistent with the literature on manualized treatments for PTSD. CETMA applies a culturally validated, 15 session protocol of PE. However, sessions ranged from 1-91 sessions. Services at this clinic are provided by graduate students in psychology and medical students on their rotations; services provided by trainees may be longer. Also, patients in this database had comorbidities with other anxiety disorders, which may lengthen the number of sessions. For patients with PTSD, more than a third of patients reported therapeutic gains (i.e., treatment goals accomplished, partial or full remission) while also more than a third opted out of treatment (schedule conflicts, patient decided not to continue with treatment). Though the database did not provide enough information for conclusive explanations, a possible reason could be the type of treatment used (PE). Because of directly confronting avoidance, PE may be difficult for some patients (Kurz, 2015). A systematic review and metanalysis of dropout rates of psychological therapies for PTSD found a mean dropout of $22 \%$ for PE (Lewis et al., 2020). Imel et al. (2013) found a two-fold increase in treatment dropout for trauma specific treatments (including PE) when compared to present centered therapy. Future research on patients' reasons for treatment termination, employing a rigorous definition, could give light in this respect.

While we are contributing to the study of PTSD in a Latino treatment-seeking population, these results must be evaluated in the context of the following limitations. First, current analyses are based on preliminary diagnoses from the initial screening interview, where a student-clinician, and their clinical supervisor, assess if a prospective patient complies with CETMA inclusion criteria. Second, the database did not include results from the Clinician Administered PTSD Scale (CAPS, the gold standard for PTSD diagnosis), administered in later sessions. Third, some associations are based on a limited number of observations, which precludes making strong inferences from our results.

\section{CONCLUSION}

In conclusion, this research study provides valuable data from a specialized, evidence-based center for Puerto Ricans, and people from the United States in the Caribbean. Results highlight the importance of implementing structured screening, and data gathering procedures, for a rigorous analysis of the key characteristics of mental health treatment-seeking individuals. These procedures are utterly important for informed education campaigns, the development of public policy, and resource allocation for a population who has recently experienced several potentially traumatic events.

Acknowledgement: We thank Dr. Estela Estapé for the feedback in the development of this article.

Funding: This project is partially supported by The National Institute of Health HCTRECD R25MD007607, from the National Institute on Minority Health and Health Disparities. The content is 
Posttraumatic Stress Disorder among Patients at an Anxiety Clinic in Puerto Rico

solely the responsibility of the authors and does not necessarily represent the official views of the National Institutes of Health.

Declaration of Conflicting Interests: The author(s) declared no potential conflict of interest with respect to the research, authorship, and/or publication of this article.

Approval of the Institutional Review Board (IRB): Medical Sciences Campus, University of Puerto Rico (Approval \#A3910119).

Informed Consent: All participants completed an informed consent.

Review Process: This study has been double-blind peer-reviewed.

\section{REFERENCIAS}

Bahamonde, M. E. (2006). Experiencias traumáticas y sintomatología de trastorno de estrés post traumático en una muestra de estudiantes universitarios. Unpublished doctoral dissertation, Pontificia Universidad Católica, Puerto Rico.

Bovin, M. J., Wells, S. Y., Rasmusson, A., Hayes, J., \& Resick, P. A. (2015). Posttraumatic stress disorder. In P. Emmelkamp \& T. Ehring (Eds.), The Wiley handbook of anxiety disorders (pp. 457496). Wiley.

Breslau, N., Kessler, R. C., Chilcoat, H. D., Schultz, L. R., Davis, G. C., \& Andreski, P. (1998).

Trauma and posttraumatic stress disorder in the community: The 1996 Detroit Area Survey of Trauma. Archives of General Psychiatry, 55, 626-632. http://dx.doi.org/10.1001/archpsyc.55.7.626

Chen Chang, J., Ming-Fang, A., Li-Sheng S., Yueh, S., Ching, J., \& Shoun Lee. (2017). Cormorbid diseases as risk factors for incident PTSD in a large community cohort. Nature Scientific Reports, 7(41276), 1-8. http://dx.doi.org/10.1038/srep41276

Frueh, B. C., Grubaugh, A. L., Madan, A., Neer, S. M., Elhai, J., \& Beidel, D. C. (2018). Evidence based practice for posttraumatic stress disorder. In D. David, S. J. Lynn \& G. H. Mostgomery (Eds.), Evidence-based psychotherapy (pp. 157-188). Wiley.

Gabalawy, R., Blaney, C., Tsai, C., Sumner, J. A., \& Pietrzak, R. H. (2018). Physical health conditions associated with full and subthreshold PTSD in U.S. military veterans: Results from the National Health and Resilience in Veterans Study. Journal of Af$\begin{array}{llll}\text { fective } \quad \text { Disorders, } & 227 & \text { (2018), } & \text { 849-853. }\end{array}$ https://doi.org/10.1016/j.jad.2017.11.058

Ginzburg, K., Ein-Dor, T., \& Solomon, Z. (2010). Comorbidity of posttraumatic stress disorder, anxiety, and depression: a 20year longitudinal study of war veterans. Journal of Affective Disorders, 123, 249-257.

González Barrios, P., Morales-Rodríguez, C. M., Lampón, A., González, R., Martínez, K. (2016). Dimensional assessment of anxiety in Puerto Rican patients: evaluating applicability of psychological questionnaires. Puerto Rico Health Sciences Journal, 35(3), 134-141.

Imel, Z. E., Laska, K., Jakcupcak, M., Simpson, T. L. (2013). Metaanalysis of dropout in treatments for posttraumatic stress disorder. Journal of Consulting and Clinical Psychology, 81(3), 394404. https://doi.org/10.1037/a0031474
Kessler, R. C., Sonnega, A., Bromet, E., Hughes, M., \& Nelson, C. B. (1995). Posttraumatic stress disorder in the National Comorbidity Survey. Archives of General Psychiatry, 52, 1048-1060. http://dx.doi.org/10.1001/archpsyc.1995.03950240066012

Kilpatrick, D. G., Badour, C. L., \& Resnick, H. S. (2017). Trauma and posttraumatic stress disorder prevalence and sociodemographic characteristics. (2017). In S. N. Gold (Ed.), APA handbook of trauma psychology (69-85). American Psychological Association.

Kimerling, R., Allen, M.C. \& Duncan, L.E. (2018). Chromosomes to Social Contexts: Sex and Gender Differences in PTSD. Current $\begin{array}{llll}\text { Psychiatry } & \text { Reports, } & 20 & \text { (114), }\end{array}$ https://doi.org/10.1007/s11920-018-0981-0

Kitsmiller, E. (2017). Health behaviors in military veterans with and without PTSD. Unpublished doctoral dissertation. University of Central Florida. Florida, United States.

Kurz, J. (2015). Improving utilization of and adherence to treatment for post-trauamtic stress disorder among U.S. servicemembers and veterans [Doctoral dissertation]. Pardee RAND Graduate School in Santa Monica, California. https://www.rand.org/content/dam/rand/pubs/rgs dissertations/RGSD300/RGSD360/RAND RGSD360.pdf

Lewis, C., Roberts, N., Gibson, S., Bisson, J. L. (2020). Dropout from psychological therapies for posttraumatic stress disorder (PTSD) in adults: systematic review and metaanalysis. European Journal of Psychotraumatology, 11(1707709), 1-22. https://doi.org/10.1080/20008198.2019.1709709

Lewis, C., Roberts, N. P., Andrew, M., Starling, E., \& Bisson, J. I. (2020). Psychological therapies for posttraumatic stress disorder: A systematic review and meta-analysis. European Journal of Psychotraumatology, 11(1), 172-215. https://doi.org/10.1080/20008198.2020.1729633

Liddon, L., Kingerlee, R., \& Barry, J.A. (2018). Gender differences in preferences for psychological treatment, coping strategies, and triggers to help-seeking. Journal of Counseling, (2018), 3138. https://doi.org/10.1111/bjc.12147

Magruder, K.M., McLaughlin, K.A., Elmore, D.L. (2017). Trauma is a public health issue. European Journal of Psychotraumatology, 8(1), 1-9. https://doi.org/10.1080/20008198.2017.1375338

Orengo-Aguayo, R., Stewart, R. W., de Arellano, M., Suárez-Kindy, J. L., \& Young, Y. (2019). Disaster exposure and mental health among Puerto Rican youth after hurricane Maria. JAMA Network Open, 2(4), 1-10. https://doi:10.1001/jamanetworkopen.2019.2619

Overstreet, C., Berenz, E. C., Sheerin, C., Amstadter, A. B., Canino, G., \& Silberg, J. (2016). Potentially traumatic events, posttraumatic stress disorder, and depression among adults in Puerto Rico. Frontiers in Psychology, 7(1), 1-7. https://doi.org/10.1037/tra0000168

Scaramutti, C., Salas-Wright, C. P., Vos, S. R., \& Schwartz, S. J. (2019). The mental health impact of hurricane Maria on Puerto Ricans in Puerto Rico and Florida. Disaster Medicine \& Public Health Preparedness, 13(1), 24.27.

Souto de Castro Longo, M., Pereira Vilete, L. M., Figueira, I., 
Quintana, M. I., Feijó Mello, M., Bressand, R. A., Mari, J., Silva Ribeiro, W., Baxter, S., Silva Freire, E. (2020). Comorbidity in post-traumatic stress disorder: A population-based study from two largest cities in Brazil. Journal of Affective Disorders, 263, 715-721. https://doi.org/10.1016/i.jad.2019.11.051

Spinhoven, P., Penninx, B. W., van Hemert, A. M., Rooji, Mark de, Elzinga, B. M. (2014). Comorbidity of PTSD in anxiety and depressive disorders: Prevalence and shared risk factors. Child Abuse $\mathcal{E} \quad$ Neglect, 38(8), 1320-1330. https://doi.org/10.1016/j.chiabu.2014.01.017

Subervi, A., Rodríguez-Arroyo, M., Alvarado, J., Roche-Miranda, M. I., Martínez, K. G. (2020, May 29th). Evaluating ataque de nervios amongst patients at CETMA anxiety clinics. Retrieved

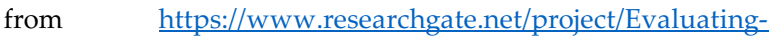

Ataque-de-Nervios-amongst-patients-at-CETMA-anxiety$\underline{\text { clinics }}$

Tarrier, N., Gregg, L. (2004). Suicide risk in civilian PTSD patients. Social Psychiatry and Psychiatric Epidemiology, 39(8), 655-661.
Puerto Rico. $\quad$ https://www.census.gov/library/stories/2019/09/puerto-rico-outmigration-increasespovertydeclines.html\#: :text=The\%20poverty $\% 20$ rate $\% 20 \mathrm{in} \% 20$ Puerto, state $\% 20$ poverty $\% 20$ rates $\% 20$ in $\% 202018$

United States Census Bureau. (n.d.). Quick facts: Puerto Rico. Retrieved August 17th, 2020, from: https://www.census.gov/quickfacts/PR

Valentine, S. E., Marques, L., Wang, Y., Ahles, E. M., DeSilva, D., \& Alegría, M. (2019). Gender differences in exposure to potentially traumatic events and diagnosis of Posttraumatic Stress Disorder by racial and ethnic group. General Hospital Psychiatry, 61, 60-68. https://doi.org/10.1016/j.genhosppsych.2019.10.008

Vera, M., Juarbe, D., Hernandez, N., Oben, A., Perez-Pedrogo, C., \& Chaplin, W. F. (2012). Probable Posttraumatic Stress Disorder and Psychiatric Co-morbidity among Latino Primary Care Patients in Puerto Rico. Journal of Depression \& Anxiety, 1(5), 116. https://doi.org/10.4172/2167-1044.1000124

United States Census Bureau. (2019, September). Poverty in

Obra bajo licencia de Creative Commons Atribución 4.0 Internacional (CC BY 4.0).

(C) 2020 Autores. 